\title{
O cavaleiro andante de destemido coração: Celso Furtado e a saudade do futuro
}

\section{The Celso Furtado's brave heart and the "missing" of the future}

\author{
Rogério Naques Faleiros ${ }^{a}$ \\ (D) https://orcid.org/0000-0003-1209-8458 \\ Ednilson Silva Felipe \\ (D) https://orcid.org/0000-0002-4147-2069 \\ Daniel Pereira Sampaio ${ }^{a}$ \\ (D) https://orcid.org/0000-0002-6130-2753
}

Resumo: Celso Furtado oferece uma vasta literatura para pensar o Brasil por uma perspectiva desde a América Latina, construindo um aporte teórico marcado pela discussão do subdesenvolvimento, criatividade e dependência, que permite a avaliação crítica da realidade brasileira. A materialização de sua teoria encontra aplicação no desenho de um projeto nacional de desenvolvimento, marcado pela reflexão teórica e ação concreta, na busca de superação das amarras colocadas ao desenvolvimento brasileiro.

Palavras-chave: Celso Furtado. Desenvolvimento. Subdesenvolvimento. Brasil. Autoritarismo.
Abstract: Celso Furtado offers a vast literature to think about Brazil from a Latin American perspective, constructing a theoretical contribution marked by the discussion of underdevelopment, creativity and dependence, that allows the critical evaluation of the Brazilian reality. The materialization of his theory finds application in the design of a national development project, marked by theoretical reflection and concrete action, in the search of overcoming the moorings placed in Brazilian development.

Keywords: Celso Furtado. Development. Underdevelopment. Brazil. Authoritarianism. 
Havia que cuidar do imediato. O cachorro, meu companheiro de longas caminhadas nas areias da praia, dei-o ao filho do vizinho, que dele se afeiçoara. O que havia de utensílios de copa e cozinha, dei-os à senhora que cuidava da casa [...]. Dois dias depois de meu enclausuramento voluntário, visitou-me um dos mais graduados militares - eram vários, quase todos especialistas - que trabalhavam sob minhas ordens na Sudene e nas empresas por ela criadas. Mostrou-me constrangido um papel assinado pelo comandante do IV Exército incumbindo-o de me substituir, pequeno fato que vinha me alertar que já não vivíamos em estado de direito, instalara-se no país uma ditadura militar.

Celso Furtado, A fantasia desfeita, 1989

momento de retornar aos clássicos. Este texto foi escrito entre setembro e outubro de 2018 , às vésperas das eleições dos cargos legislativos e executivos em nível estadual e federal. Contexto duro, difícil, de refregas intermináveis e de aparente triunfo dos desavisados. Como diria Nelson Rodrigues “a ignorância perdeu a sua modéstia [e a vergonha]", e aquilo que parecia sepultado no passado retorna à cena enfurecido e armado, tal como Hades, filho de Cronos e Reia, que na mitologia grega representa o mundo dos demônios e das profundezas. Novamente nos vemos entre, de um lado, a democracia e sua defesa, e, de outro, o conservadorismo militarista galopante, situando-nos à beira do abismo. Os mais otimistas, como nós, esperavam que após três décadas de abertura política as instituições democráticas tivessem definitivamente se enraizado em nossa sociedade e em seu conjunto de valores éticos e morais, consubstanciados no pacto social da Constituição de 1988. Contudo, nos vemos em face de nova cruzada contra a democracia e a liberdade.

O esgarçamento político ocorre no contexto da maior crise econômica da história republicana do país. Em 2014 o Produto Interno Bruto brasileiro (PIB) cresceu apenas 0,5\%. Seguidamente, em 2015 e 2016, o PIB diminuiu em 3,5\%. Já em 2017 registramos um tímido crescimento de 1,0\%, com projeções otimistas de $1,4 \%$ para 2018. Definitivamente, a economia nacional enfrenta dificuldades na busca de novo modelo de desenvolvimento 
e num contexto internacional nada auspicioso, no qual ainda não foram vislumbradas soluções concretas para a crise do capital. Em decorrência do baixo dinamismo, os dados da Pesquisa Nacional por Amostra de Domicílios (PNAD) produzida pelo Instituto Brasileiro de Geografia e Estatística (IBGE) indicam, para o segundo trimestre de 2018, a existência no país de 13 milhões de desempregados, um cenário social tenebroso. 0 trabalho por conta própria, muitas vezes informal, já é uma realidade na vida de um em cada quatro brasileiros.

As discussões sobre o desenvolvimento econômico, ou sobre o subdesenvolvimento e seu enfrentamento, parecem superadas no atual contexto. Poucas são as alternativas viáveis que apontam para o estabelecimento de um centro interno de decisões (em termos furtadianos), num contexto de consolidada transnacionalização do capital que indica permanência na longa duração histórica. Tal lógica, caracterizada pela integração dos mercados financeiros, reduziu a soberania na política econômica e tornou cada vez mais difícil a aplicação de uma política monetária autônoma que não seja de caráter recessivo (Furtado, 1992, p. 15), condenando o Brasil à interrupção de suas possibilidades de progressos material, cultural e civilizacional, ou seja, de seu projeto próprio de futuro.

O dramático quadro de crise foi assim descrito por Furtado em 1993:

Hoje em dia vivemos em uma época marcada por perda total de rumo. Houve época em que existia uma utopia, o homem da civilização ocidental viveu sempre agarrado em alguma utopia, com a ideia de que o futuro pertence a um ser superior. Os gregos tinham uma ideia de futuro bem pessimista, consideravam que o passado é que era importante, e os mitos estavam no passado. A civilização ocidental é marcada por isso tudo, e a própria ideia de providência, que está no pensamento de todo cristão, liga-se a isso. Acontece que pela primeira vez nos encontramos diante de uma espécie de vazio. 0 futuro é um buraco negro que resulta, a meu ver, essencialmente do caminho que tomaram a ciência e a tecnologia. A ação do homem sobre o planeta, embora baseada no conhecimento científico, mudou a interpretação do mesmo planeta e levou a essa situação gravíssima de destruição da base de recursos naturais, à camada de ozônio, a toda a tragédia ecológica. Tudo isso nos leva 
hoje a uma situação de pessimismo, de incerteza com respeito ao futuro. (Kugelmas, 2011, p. 380)

É justamente nesse adverso contexto, já descrito pelo autor no início dos anos 1990, que assumimos a tarefa de apresentar aos leitores alguns pontos relevantes e atuais do edifício teórico-histórico de Celso Furtado e de seu projeto social, bem como o diagnóstico das dificuldades da nação e do povo frente ao neoliberalismo e seus correlatos câmbios estruturais. Seria hoje o pensamento do autor capaz de iluminar os caminhos para um novo plano nacional de desenvolvimento? Reunimos condições de desfazer as amarras da dependência econômica e cultural que assolam o Brasil nos quadros da transnacionalização do capital?

\section{O “demiurgo" e o diagnóstico: o subdesenvolvimento}

Deixemos de lado a obra Formação econômica do Brasil, publicada em 1959 e sobejamente conhecida, não por não a considerarmos uma obra-prima do tensionamento entre história e teoria e de aplicação do método histórico-estrutural, paradigma de toda uma geração de pesquisadores e formuladores de políticas na América Latina. O faremos porque não acrescentaríamos nada superior àquilo destacado por Francisco de Oliveira em seus ensaios sobre Celso Furtado (Oliveira, 2003, p. 83-102) e em coleção de artigos organizada em comemoração aos cinquenta anos do livro clássico organizado por Araújo, Vianna e Macambira (2009).

Tratemos aqui de Desenvolvimento e subdesenvolvimento, livro publicado em 1961. Nessa obra Furtado pontua os elementos para uma teoria do subdesenvolvimento, indicando que o modelo clássico de desenvolvimento industrial, na forma como concebidos nos grandes centros universitários do mundo ocidental, possui propósitos limitados aos objetivos das periferias do sistema (Furtado, 1961, p. 163), dado que apresentam a falha fundamental de ignorar que o desenvolvimento econômico possui nítida dimensão histórica, 
em crítica direta e a autores do pós-guerra, como Kaldor, Harrod e Domar. ${ }^{1}$ Assim, libertando-se das amarras dos modelos em sua primeira obra de caráter teórico mais amplo, Furtado indica que um modelo abstrato, derivado de uma experiência histórica limitada e às articulações de determinadas estruturas, não pode pretender elevado grau de generalidade (Idem, p. 164). Referindo-se às economias desenvolvidas, o autor assim analisa a questão de sua derivação e validade histórica:

Nesse processo só influíram, de maneira fundamental, condições específicas de algumas nações, sobretudo da Inglaterra e dos Estados Unidos, países que, sob vários pontos de vista, constituíram um só sistema econômico. Derivar um modelo abstrato de mecanismo dessas economias, em seu estágio atual, e atribuir-lhe validez universal valeria por uma reencarnação do Homo oeconomicus, em cuja psicologia rudimentar os clássicos pretenderam assentar as leis econômicas fundamentais. A dualidade óbvia que existe e se agrava, cada dia mais, entre as economias desenvolvidas e as subdesenvolvidas, exige uma formulação desse problema em termos distintos. (Furtado, 1961, 178; grifos nossos)

O aumento da produtividade impactava positivamente sobre a massa salarial, considerando-se, como ponto de partida, a mais equânime distribuição de renda e correlata homogeneidade social. Ademais, as pulsões pelo aumento da produtividade atravessavam a totalidade das cadeias produtivas, estabelecendo um círculo virtuoso entre os setores produtores de bens de capitais e os produtores de bens de consumo, ou, nas palavras do próprio autor, constituíam um só sistema econômico. Salienta-se em Furtado o primado do mercado interno sobre a formação do produto, sendo as exportações complementares à dinâmica interna. Senão, vejamos a seguir:

1 Nicholas Kaldor em "A model of economic growth" (1971), Harrod em "An essay in dinamic theory" (1949) e Domar em "Capital expansion, rate of growth and employment" (1947). Citamos também Paul Rosenstein-Rodan e W. Arthur Lewis. 
Figura 1. Círculo virtuoso de expansão em economias desenvolvidas

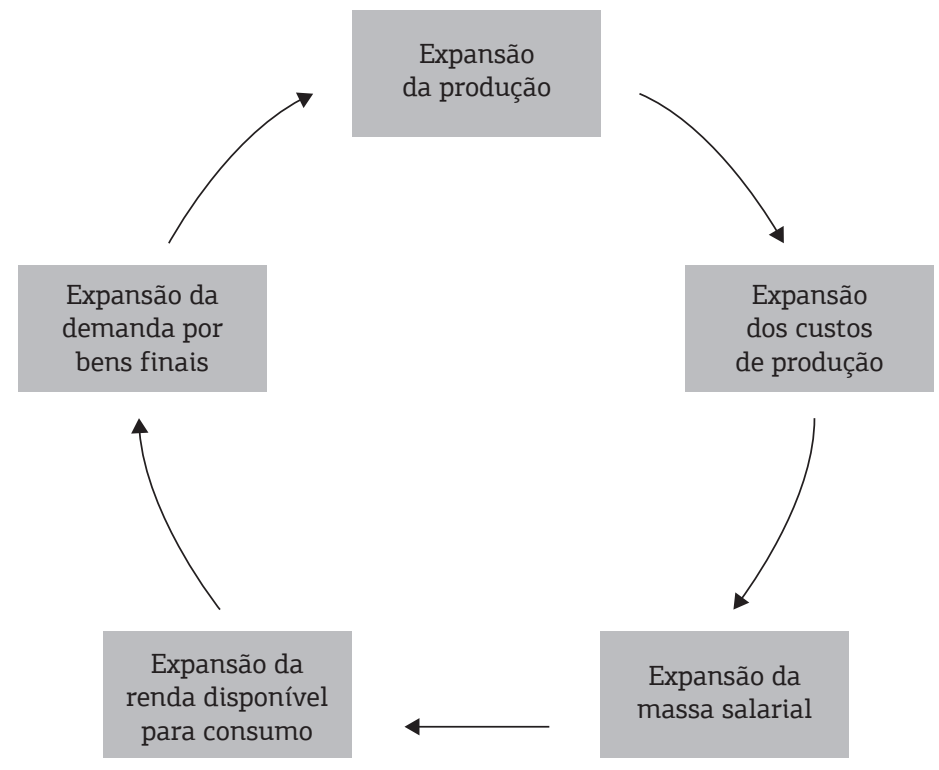

Fonte: Elaboração própria a partir de Furtado (1975).

Os efeitos vistos acima, em função de uma série de determinações históricas, não reuniam condições objetivas de ser repetidos nos países de passado colonial (escravidão), a despeito de influenciarem toda uma família de modelos típicas do mainstream.

Em percepção ao vazio teórico existente na análise das trajetórias históricas dos países pobres, Furtado ofereceu sua maior contribuição ao Brasil e à América Latina: a teoria do subdesenvolvimento, num esforço de "pensar em si a partir de si”, afrontando qualquer complexo de vira-latas. Vêm à tona o passado colonial, a questão da oferta de mão de obra, as relações centro-periferias, a divisão internacional do trabalho, a heterogeneidade estrutural, a distribuição do excedente econômico e o desenvolvimento desigual, elementos centrais na análise. $O$ autor constata que o impacto da expansão do capitalismo sobre as estruturas arcaicas variou de região para região, ao sabor de circunstâncias locais, do tipo de penetração capitalista e da intensidade desta. Contudo, a resultante foi, quase sempre, a criação de estruturas híbridas, uma parte das quais tendia a comportar-se como um 
sistema capitalista, a outra, a manter-se dentro da estrutura preexistente (Furtado, 1961, p. 180).

O subdesenvolvimento, então, é caracterizado como um "processo histórico autônomo, e não uma etapa pela qual tenham, necessariamente, passado as economias que já alcançaram grau superior de desenvolvimento" (Idem). Cada nação é única em seu processo de desenvolvimento, sendo que a compreensão desses processos deve levar em conta, com todas as suas especificidades; i) as relações entre países, no contexto de uma divisão internacional do trabalho, ii) o padrão de acumulação da riqueza instalado ao longo do tempo, e iii) a reprodução do subdesenvolvimento, pois os seus mecanismos não são estáticos, mas mutáveis no tempo e no espaço, considerando o padrão de acumulação vigente e as relações estabelecidas com as distintas hegemonias.

Os efeitos da difusão tecnológica em países subdesenvolvidos serão diametralmente opostos em relação ao que vimos anteriormente. À expansão da produção corresponde a um padrão de difusão tecnológica que não atende às especificidades das periferias, visto que não dominam o núcleo de inovação e tecnologia e incorporam tecnologias não compatíveis com suas necessidades, redundando em expansão não proporcional dos custos de produção. Aqui age a heterogeneidade estrutural, tanto no nível regional quanto no das classes sociais, étnico e racial. ${ }^{2}$ Ademais, em função da dupla realidade que caracteriza os países de passado colonial, qual seja, a percepção de um setor moderno e dinâmico em convivência com um setor arcaico e estagnado (no nível da produtividade), verifica-se também o problema das escalas e escopos de produção, não adequado às realidades latino-americanas e, portanto, disfuncional à distribuição de renda.

À expansão desproporcional dos custos de produção corresponde a expansão concentrada da massa salarial em regiões mais modernizadas e industrializadas da periferia, em geral ultradinâmicas e caracterizadas por alguma mobilidade social, situação que encaminha, evidentemente, às crônicas e gritantes desigualdades regionais dentro de um mesmo país. Nesse quadro, a expansão da demanda por bens de consumo finais precisará de uma classe social ungida e com poder de compra suficientemente dilatado

2 Ver F. Fernandes, 1976. 
para efetivar o consumo conspícuo no nível do padrão de consumo das elites e classes médias altas internacionais e cosmopolitas. Vejamos abaixo a síntese do argumento:

Figura 2. Círculo vicioso da exclusão e da desigualdade

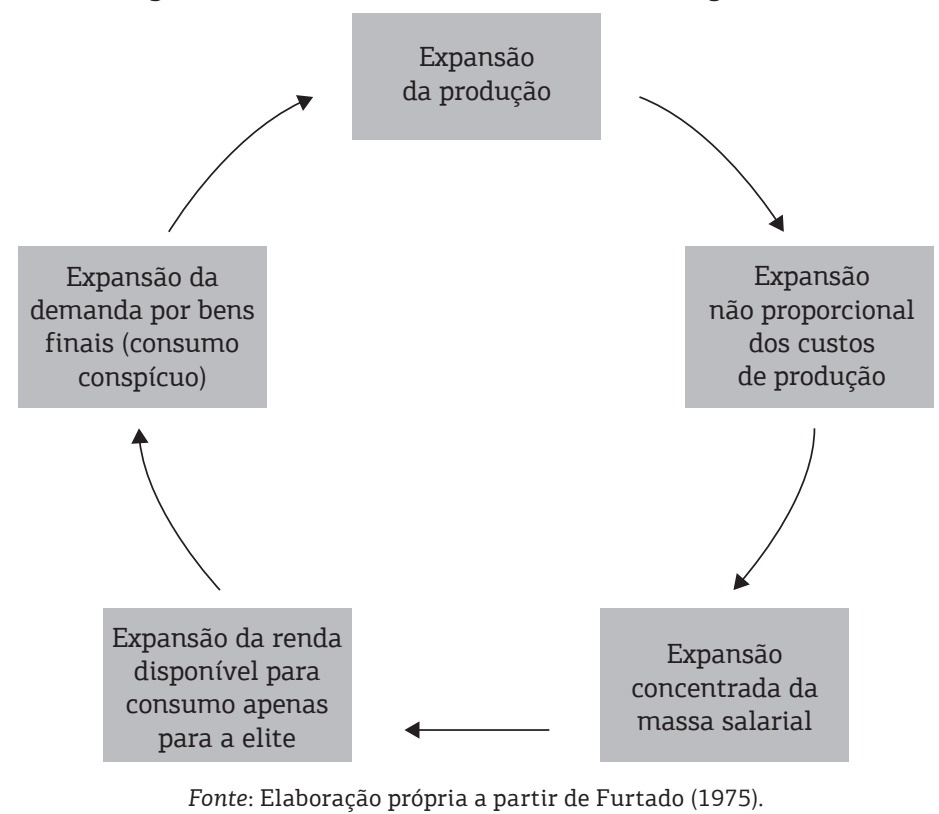

Permanecerá então a heterogeneidade tecnológica e estrutural, mantendo-se a elasticidade de mão de obra. Furtado, mais uma vez, é certeiro no diagnóstico:

Num sentido objetivo, esse tipo de acumulação [nas periferias] cria antinomias sociais mais agudas do que aquelas que caracterizaram o desenvolvimento do capitalismo nos países que conheceram a revolução burguesa. Mas as projeções no plano político estão longe de ter a mesma relevância. De uma ou outra forma, a massa da população é mantida sob tutela: a participação no processo político da massa assalariada faz-se sob o controle de grupos que integram a estrutura tradicional de poder. [...] Ora, dada a especificidade dos problemas que nesses 
países [periferias] coloca a intensificação da acumulação, a inventividade no plano das formas sociais é tanto ou mais importante do que em outros contextos. A tendência ao mimetismo, alimentada pela dominação ideológica, substitui uma forma de imobilismo por outra. (Furtado, 1978, p. 77-82)

Há que se destacar também o papel institucional neste processo, pois o Estado, tendo o Brasil como exemplo, cumprirá tarefas importantes no que se refere ao mecanismo fiscal e cambial, possibilitando alguma margem de previsibilidade ao investimento externo, bem como a efetivação de investimentos diretos em infraestrutura. Ademais, caberá também ao Estado: i) o alongamento da escala salarial, na promoção de arrochos típicos de períodos autoritários (mas não somente), ii) a garantia de crédito subsidiado às elites e empresas transnacionais via bancos de desenvolvimento, ou mesmo a garantia de recursos via deslavada corrupção típica do período militar; ${ }^{3}$ iii) a manutenção e ampliação de formas de rentismo (vide as reformas do Paeg, por exemplo); iv) o manejo dos ganhos inflacionários a partir de aplicações financeiras inacessíveis aos de baixo e a legitimação do distanciamento do padrão de vida dos mais ricos em relação aos mais pobres.

Senão, vejamos. Optando por uma observação de longo prazo, temos abaixo a evolução real do salário mínimo entre 1940 e 2018. Nela podemos notar como, após a Consolidação das Leis do Trabalho (CLT), vivenciamos paulatinos aumentos reais e significativos no salário mínimo, frutos, evidentemente, de maior conscientização política e contestação popular típicas de um regime político aberto. Destaca-se aqui o Estatuto do Trabalhador Rural de 1963, a partir do qual o salário mínimo foi estendido a esses trabalhadores. Com o golpe civil-militar de 1964, essa tendência é refreada automaticamente, intensificando-se o que poderíamos chamar de acumulação predatória (à brasileira), que estabelece paradigmas de elevada concentração da riqueza. Apenas para exemplificar, enquanto na Alemanha, então Ocidental, em 1980, a participação dos salários no PIB era de 50\%, no Brasil, para o mesmo ano, era de $17 \%$. De fato, a comparação com um país desenvolvido pode não fazer

3 Ver o livro de Pedro Henrique Campos, Estranhas catedrais: as empreiteiras brasileiras e a ditadura civil-militar, 1964-1988, publicado em 2014. 
muito sentido; consideremos então o México: nesse país, para o mesmo ano, a participação dos salários no PIB era de 37\% (Costa, 1997, p. 64).

Desde a República Nova (cujo ciclo político aparentemente se encerrou em 2016), o salário mínimo em termos reais tem retomado, em especial após 2003, uma trajetória ascendente mais destacada. Contudo, ainda estamos distantes dos níveis anteriores ao golpe de 1964, duramente interrompidos pelo 31 de março - o dia que durou 21 anos. Fato é que o cerceamento democrático e a impossibilidade de mobilizações coletivas, somados à dura interrupção do modelo que aparentemente caminhava para uma melhor distribuição de renda, ampliou e perpetuou efeitos nefastos sobre a economia e a política brasileira: a pobreza aliada à falta de politização.

Figura 3. Salários mínimos reais - 1940-2018

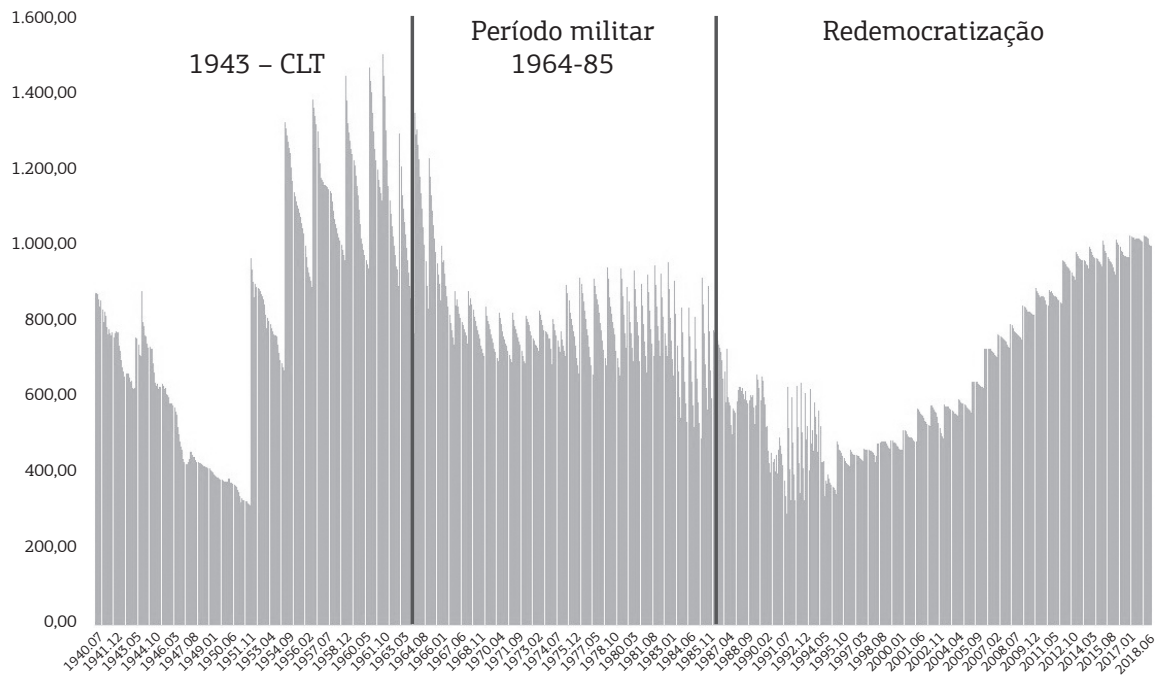

Fonte: Elaboração própria a partir de www.ipeadata.gov.br. Obs.: série em reais $(\mathrm{R} \$)$ constantes do último mês, elaborada pelo Ipea, deflacionando-se o salário mínimo nominal pelo Índice Nacional de Preços ao Consumidor (INPC) do IBGE a partir de março de 1979. Para períodos anteriores, os deflatores utilizados foram o IGPC-Mtb (jan./1948-mar./1979), o IPC-RJ/FGV (jan./1944-jan./1948) e o IPC-SP/Fipe (jul./1940-jan./1944). O salário mínimo urbano foi instituído no Brasil por decreto-lei do presidente Getúlio Vargas, durante o Estado Novo, e começou a vigorar em julho de 1940, com valores diferenciados entre estados e sub-regiões. Em 1943, foi incorporado à Consolidação das Leis do Trabalho (CLT) e, em 1963, foi estendido ao campo por meio do Estatuto do Trabalhador Rural. Foi nacionalmente unificado em maio de 1984, mas, desde 2000, a Lei Complementar n. 103 permite que os estados fixem pisos estaduais superiores ao mínimo nacional. Os dados dessa série para o período em que a legislação federal definia faixas diversificadas referem-se sempre ao maior salário mínimo vigente no país. 


\section{O "demiurgo" e o projeto: sobre mitos e criatividade}

No início dos elos descritos na Figura 2, retomando-se a expansão da produção (o que merece um destaque à parte, deve-se considerar os imbricados mecanismos que reforçam a dependência. Dos recursos de domínio dos quais dispõem os países centrais, na estrutura de poder internacional, o mais robusto é o controle da tecnologia. Por esse caminho, as empresas transnacionais, sobretudo a partir de 1973, miraram nas periferias como importante fonte de recursos do mercado financeiro, a partir dos quais as empresas transnacionais utilizaram o poder de ares.

Nesse processo de transplantação, evidentemente, o controle da empresa (filial) e representantes de seus departamentos de marketing, de produção e financeiro deverão ser transferidos progressivamente para centros de decisão internos do país. Se o controle local se estende a muitos setores em função da complexidade do mercado em mira (é este o caso do Brasil), cria-se uma massa crítica que permite pressionar as transnacionais para que cedam a tecnologia em condições menos onerosas. Segundo Furtado, torna-se possível orientar a tecnologia em função de objetivos definidos e criar um mercado para a tecnologia localmente produzida. Entretanto, os propósitos dessa política podem frustrar-se totalmente se a referida massa crítica não é obtida (Furtado, 1978, p.108). Nesse ponto, o autor, parece chegar ao busílis da questão, ao relacionar a implementação de transnacionais em países latino-americanos aliada à não transferência de tecnologia e a via autoritária e entreguista, naufragando qualquer possibilidade de constituição de um centro interno de decisões, sobretudo na ditadura militar. Mais uma das heranças do golpe civil-militar de 1964. Vejamos como a ideia foi desenhada em 1962.

A questão do centro interno de decisões, embora presente em Criatividade e dependência na civilização industrial, de 1978, já estava esboçado em A pré-revolução brasileira, de junho 1962. Nessa obra, já com entendimento maduro sobre o subdesenvolvimento e acumulando a lida à frente da Sudene, lembrando que viria a assumir o Ministério do Planejamento em setembro, Furtado nos brinda com brilhante exercício de conjuntura ao antever o golpe militar, escrevendo um livro inspirado pela filosofia da ação. Segundo o autor, em 1962 (p. 9), 
A economia de nosso país alcançou um grau de diferenciação - o que é distinto do nível convencional de desenvolvimento medido pela renda per capita - que permitiu transferir para o país os principais centros de decisão de sua vida econômica. Em outras palavras: o desenvolvimento recente da economia brasileira não se fia apenas no sentido de elevação da renda média do habitante do país, mas também assumiu a forma de uma diferenciação progressiva do sistema econômico, o qual conquistou crescente individualização e autonomia. O Brasil está repetindo, até certo ponto, a experiência do Japão em decênios anteriores: a conquista da autodeterminação no plano econômico ainda em fase caracterizada por um nível de renda per capita típico de país subdesenvolvido. Como decorrência dessa modificação estrutural, aumentou grandemente a eficácia de nossas decisões no plano da política econômica.

Furtado assume dupla premissa: i) que um regime político aberto proporcionou ganhos, produtividade e complexidade econômica, a ponto de internalizarmos parcela das decisões (estratégicas sob ponto de vista do Estado brasileiro) e; ii) que o marxismo, em que pese a influência que exercia sobre a juventude à época, não constituía modelo para o Brasil.

A estratégia, já na antessala do golpe, era desqualificar as experiências socialistas fixando olhar na relação liberdade versus desenvolvimento. Afirma Furtado (1962, p. 22): “Se chegássemos a admitir como tese válida que o desenvolvimento econômico dos países socialistas foi contrapartida do cerceamento das liberdades cívicas, deveríamos também aceitar como verdadeiro o corolário de que o preço da liberdade que fruímos é o retardamento do desenvolvimento econômico geral". Mirando à esquerda e à direita, o reformista Celso Furtado não enxergava nesses paradigmas possibilidades de desenvolvimento em sociedade aberta. A luta, ali, era pelo avanço das reformas de base, pela conquista de formas superiores de organização político-social - ainda circunscritas à classe operária, mas não aos camponeses - e pelo avanço vertical da industrialização em típico catching up (convergência ou aproximação tecnológica).

De resto, o problema da estrutura agrária era premente. Numa economia capitalista, a escassez permanente de mão de obra pressiona no sentido da elevação dos salários reais, o que, por seu lado, estimula fortemente as 
inovações tecnológicas de tipo saving labor. O avanço tecnológico acelerado constitui base para a manutenção da taxa de lucro, e para evitar o colapso da demanda efetiva e o desemprego é indispensável que esses lucros sejam absorvidos pela economia em fluxo contínuo de novas inversões, ou seja, que a economia continue crescendo, indicando que a política de pleno emprego traz em si uma política de desenvolvimento. Na crise econômica que já se anunciava em 1962, no rescaldo da industrialização por substituição de importações (ISI) e seus desequilíbrios, Furtado indica que as reformas de base (e o Plano Trienal) deveriam ser compreendidas como fatores que possibilitariam o ataque aos desajustamentos estruturais advindos da questão agrária.

A preocupação recai em especial sobre o Nordeste brasileiro, que, nas palavras do autor, "não podendo concorrer, traumatiza-se ou desagrega-se" (Furtado, 2004, p. 113). Era necessário para Furtado um rápido processo de industrialização e, simultaneamente, reconstruir sobre novas bases a economia agropecuária, o que evidentemente seria tarefa de grandes proporções com importantes implicações financeiras. Isso, segundo o autor, poderia ocorrer, considerando o efeito multiplicador, a partir de transferência de 1\% do produto líquido do Centro-sul, que geraria para o Nordeste uma taxa de investimento líquido da ordem de 7\%. A questão é assim descrita em 1962:

O caso da economia subdesenvolvida, entretanto, é distinto. A ação estatal não vem coibir a atuação do empresário privado; vem criar condições para que este surja e se consolide. [...] trata-se agora de mudança qualitativa fundamental, a economia está dotada de elemento dinâmico próprio: com os investimentos industriais apoiados no mercado interno cada novo impulso para a frente significaria maior diversificação estrutural, mais altos níveis de produtividade, maior massa de recursos, novos investimentos, expansão mais rápida do mercado interno, possibilidade de superar-se permanentemente. (Furtado, 1962, p. 40 ss.)

Em clara confrontação com as teses liberais, Furtado apresenta acima foco nas potencialidades do mercado interno e nas políticas de integração nacional (encadeadas e promovidas pelo Estado, em típico crowding in) como 
sendo elementos essenciais à superação do subdesenvolvimento. Contudo, o seu projeto para o Brasil, estilizado de maneira mais elaborada em 1969, sai derrotado, verificando-se a inviabilidade histórica de seu viático e a manutenção ampliada dos efeitos deletérios do subdesenvolvimento tal como vimos acima. As reformas de base foram congeladas, em 21 anos de aumento da desigualdade acompanhadas por alto dinamismo. As obras escritas a partir desse momento serão absolutamente críticas às estratégias de crescimento adotadas pelos governos militares. Celso Monteiro Furtado foi incluído na primeira lista de cassados pelo Ato Institucional n. 1, tendo seus direitos políticos suspensos por dez anos. Naquele momento, foi necessário deixar o cachorro com o filho do vizinho e os utensílios com a faxineira, tal como vimos na epígrafe deste texto.

Já no exílio, Furtado escreveu uma série de artigos, conferências e capítulos que viriam a compor uma de suas obras seminais: $O$ mito do desenvolvimento econômico, de 1974. Nela, em crítica ao conceito de desenvolvimento, aponta que a hipótese de generalização, no conjunto do sistema capitalista, das formas de consumo que prevaleceram à época nos países cêntricos, não tem cabimento dentro das possibilidades evolutivas aparentes deste sistema (Furtado, 1974, p. 74). O capitalismo, naquela "toada", levaria a uma ruptura cataclísmica caso se universalizasse, sendo essa uma demonstração cabal de que o estilo de vida criado pelo capitalismo industrial sempre será o privilégio de uma minoria. Em clara crítica ao modelo econômico dos governos militares e o seu "grande salto para o caos", afirma: "O custo, em termos de depredação do mundo físico, desse estilo de vida, é de tal forma elevado que em toda tentativa de generalizá-lo levaria inexoravelmente ao colapso de toda uma civilização, pondo em risco as possibilidades de sobrevivência da espécie humana" (Idem, p. 75).

Mais uma vez subjaz aqui a crítica aos modelos de desenvolvimento e suas generalizações, equivocadamente perseguida pelos militares. Dada a heterogeneidade estrutural, era possível apenas "miniaturizar", em um país periférico, o sistema industrial dos países cêntricos (aqueles onde a acumulação de capital alcançou níveis muito mais altos), o que significava introduzir no aparelho produtivo uma profunda descontinuidade causada pela coexistência de dois níveis tecnológicos distintos. Na fase de 
industrialização substitutiva, a extrema disparidade entre níveis (e o grau de diversificação) do consumo da minoria modernizada e da massa da população deverá incorporar-se à estrutura do aparelho produtivo. Dessa forma, o chamado "desequilíbrio ao nível dos fatores" deve ser considerado como inerente à economia subdesenvolvida que se industrializa. O Estado teria importante participação nas indústrias produtoras de bens intermediários, e os capitalistas locais controlariam boa parte das indústrias de bens de consumo não duráveis, ao passo que as grandes empresas controlariam as atividades que se baseiam no progresso técnico (bens de consumo duráveis e equipamentos em geral), nichos nos quais o fluxo de novos produtos e o grau de acumulação são mais intensos.

Para Furtado, então, sem o enfrentamento das reformas do sistema, a situação de dependência seria permanentemente reforçada (com a implantação de novos produtos, processos e técnicas) e com o descasamento entre o nível de acumulação e o padrão de consumo (público e privado) operado nas periferias subdesenvolvidas, tornando-se evidente que o avanço do processo de industrialização dependerá do aumento da taxa de exploração, isto é, de uma crescente concentração de renda (Furtado, 1974, p. 88). Ainda de acordo com o autor,

a característica mais significativa do modelo brasileiro é a sua tendência estrutural para excluir a massa da população dos benefícios da acumulação e do progresso técnico. Assim, a durabilidade do sistema baseia-se grandemente na capacidade dos grupos dirigentes em suprimir todas as formas de oposição que seu caráter antissocial tende a estimular. (Idem, p. 111-112)

Em síntese, quanto mais intenso o influxo de novos padrões de consumo, mais concentrada terá de ser a renda. Na esteira desse processo, e orientando-o, segue a dependência cultural, expressa pelo comportamento dos grupos que se apropriam do excedente e modelam seu consumo pelos paradigmas vindos do exterior: a tragédia do mimetismo cultural como critério de diferenciações sociais.

Tem-se nesse processo, a partir da ditadura militar e seus desdobramentos, a definitiva capitulação das classes empresariais nacionais e o 
abandono de qualquer projeto de desenvolvimento nacional e autônomo. As conexões fundamentais entre subdesenvolvimento (como fenômeno histórico-estrutural) e dependência (como fenômeno cultural) "satelizaram" o Brasil e os países latino-americanos no concerto internacional. Anos depois, Furtado formalizará a questão: "O Brasil teve sua oportunidade histórica, acumulou riqueza e poderia ter transformado essa 'modernidade' numa sociedade mais justa, mais estável. E não o fez. Perdeu sua oportunidade histórica. Perdeu-se pelo atraso social, por ter uma elite que se aliou aos Estados Unidos, preocupada estritamente em acumular para o benefício de uma minoria" (Furtado, 1995, p. 105).

\section{A saudade do futuro}

Celso Furtado faleceu em 20 de novembro de 2004. Deixou-nos a saudade do futuro. Houve um tempo neste país em que pessoas como ele acreditaram num mundo melhor, na utopia de um devir superior destinando a ciência e o conhecimento para a ação. Havia uma ordem a ser transformada; os elos de subdesenvolvimento e da dependência, mais robustos do que a terceira fase sólida do carbono, eram criativamente contestados pela história, pela teoria e pela política (nesta seara, mesmo que timidamente).

É este um primeiro ensinamento que devemos absorver do cavaleiro andante: o conhecimento é uma forma de combate, e pouco valor possui quando soberbo e desconectado dos reais problemas da sociedade. Não é por acaso que em diversas obras, e aqui citaremos três, Furtado encaminha mensagens e responsabilidades que devem recair aos jovens economistas. São elas: A pré-revolução brasileira (1962); O longo amanhecer (1999) e Em busca de novo modelo (2002), obras nas quais o autor empreende uma espécie de chamamento às novas gerações para pensar o Brasil, dado que certamente herdarão problemas ainda mais complexos dos que os tratados por ele. É como se Furtado implorasse aos neófitos da ciência econômica a atenção para a América Latina, o Brasil e o Nordeste, espaços (e tempos) das amarras do subdesenvolvimento. 
Em resposta às questões colocadas no início deste texto, responderíamos: i) Seria hoje o pensamento do autor capaz de iluminar os caminhos para um novo plano nacional de desenvolvimento? Sim, certamente suas reflexões constarão na matriz de qualquer projeto de futuro que reconheça nossa autonomia, especificidades e necessidades reais. A abordagem histórico-estrutural empreendida por Furtado só foi viabilizada em razão de sua grande capacidade de estabelecer mediações entre modelos, teoria e história. O Nordeste, como diagnóstico, e a Sudene, como ação, constituem (por exemplo) a síntese de seu pensamento, sem nunca tergiversar sobre as formas institucionais típicas de uma sociedade aberta; ii) Reunimos condições de desfazer as amarras da dependência econômica e cultural que assolam o Brasil nos quadros da transnacionalização do capital? Responder negativamente a esta questão é simplesmente negar o legado furtadiano, e não temos o direito de desistir do futuro, embora percebamos a saudade.

Em sua última obra Em busca de novo modelo. Reflexões sobre a crise contemporânea, de 2002, Celso Furtado exprime a sua derradeira crítica, aos 82 anos de idade:

O autoritarismo político, que a partir de 1964 neutralizou por duas décadas todas as formas de resistência dos excluídos, exacerbou as tendências perversas do nosso desenvolvimento mimético. Esse autoritarismo, como um deus mitológico [referência ao deus Jano], apresentou duas faces. Se por um lado, favoreceu os interesses criados da área econômica, por outro agravou o isolamento da esfera política, que adquiriu crescente autonomia sob a forma de poder tecnocrático. Implantou-se a fantasia geopolítica da "potência emergente". Aí tem uma de suas raízes o processo de endividamento externo, que nos levou a uma situação de desgoverno sem precedente. $O$ desenvolvimento, gerado endogenamente, requer criatividade no plano político, e esta se manifesta quando à percepção dos obstáculos a superar adiciona-se um forte ingrediente de vontade coletiva. (Furtado, 2002, p. 32; grifos nossos)

O país registra hoje, em decorrência do baixo dinamismo de longa duração, um grave quadro econômico, social e o desmonte do pacto social forjado na Constituição de 1988. O trabalho por conta própria, flutuante, muitas vezes informal, já é uma realidade na vida de um em cada quatro 
brasileiros. Desilusão, tristeza, depressão, falta de solidariedade. Em parte, é essa a camada que no atual contexto político tem dado corpo à ascensão de uma ditadura, se não na forma, porque estribada unicamente na frágil figura do voto, com certeza no conteúdo, travestido de militarização autoritária e cerceamento das liberdades democráticas. Desconsideram que a política é uma valiosa referência humana e esvaziam a ação (nos termos de Hannah Arendt), desabilitando-se da vida pública. A contribuição de Celso Furtado, aliás, a contribuição de uma vida, de um homem para além de seu tempo, um clássico do pensamento social brasileiro, nos alerta para o significado de um regime político fechado em situação de subdesenvolvimento e suas consequências para os mais pobres. O cavaleiro andante de destemido coração, em seu viático, deixa, para as novas gerações, o desafio de construção de uma outra sociedade, a esperança de uma espécie de "construção retomada" ainda por vir.

\section{Filmografia}

O LONGO AMANHECER - uma biografia de Celso Furtado. Direção de José Mariani. Brasil, 2007, 73 min.

PRIVATIZAÇÕES: a distopia do capital. Direção de Silvio Tendler. Brasil, 2007, 56 min.

\section{Referências}

ARAÚJO, T. P.; VIANNA, S. T. W.; MACAMBIRA, J. (Orgs.). 50 anos de formação econômica do Brasil: ensaios sobre a obra clássica de Celso Furtado. Rio de Janeiro: Ipea, 2009.

CAMPOS, P. H. Estranhas catedrais: as empreiteiras e a ditadura civil-militar, 1964-1988. Niterói: Eduff, 2014.

COSTA, Edmilson. A política salarial no Brasil: 21 anos de arrocho salarial e acumulação predatória. São Paulo: Boitempo Editorial, 1997.

FERNANDES, F. Circuito fechado: quatro ensaios sobre o poder institucional. São Paulo: Hucitec, 1976.

FURTADO, C. Desenvolvimento e subdesenvolvimento. Rio de Janeiro: Fundo de Cultura, 1961. A pré-revolução brasileira. Rio de Janeiro: Fundo de Cultura, 1962. Subdesenvolvimento e estagnação na América Latina. Rio de Janeiro: Civilização Brasileira, 1966. 
FURTADO, C. Um projeto para o Brasil. Rio de Janeiro: Saga, 1969.

. Teoria e política do desenvolvimento econômico. 4. ed. São Paulo: Cia. Editora Nacional, 1971. 4. ed.

. O mito do desenvolvimento econômico. Rio de Janeiro: Paz e Terra, 1974.

. Análise do modelo brasileiro. Rio de Janeiro: Civilização Brasileira, 1975.

1978

. Criatividade e dependência na civilização industrial. São Paulo: Círculo do Livro,

Cultura e desenvolvimento em época de crise. Rio de Janeiro: Paz e Terra, 1984.

A fantasia desfeita. Rio de Janeiro: Paz e Terra, 1989.

Brasil: a construção interrompida. Rio de Janeiro: Paz e Terra, 1992.

. O pensamento econômico latino-americano. Novos Estudos, São Paulo, n. 41. p. 96-110, mar. 1995. Entrevista concedida a Carlos Mallorquim.

Terra, 1999.

O longo amanhecer: reflexões sobre a formação do Brasil. Rio de Janeiro: Paz e

Em busca de novo modelo: reflexões sobre a crise contemporânea. Rio de Janeiro:

Paz e Terra, 2002.

Formação econômica do Brasil. 34. ed. São Paulo: Companhia das Letras, 2007.

KUGELMAS, E. Dossiê Celso Furtado. Cadernos do Desenvolvimento, Rio de Janeiro, Centro Celso Furtado, v. 6, n. 8, maio 2011.

OLIVEIRA, F. A navegação venturosa: ensaios sobre Celso Furtado. São Paulo: Boitempo Editorial, 2003.

\section{Sobre os autores}

Rogério Naques Faleiros - Professor do Departamento de Economia.

E-mail: rogerio.faleiros@ufes.br

Ednilson Silva Felipe - Professor do Departamento de Economia.

E-mail: ednilson.felipe@ufes.br

Daniel Pereira Sampaio - Professor do Departamento de Economia.

E-mail: daniel.sampaio@ufes.br 